\title{
Analysis of Wave-Induced Current Using Digital Image Correlation Techniques
}

\author{
Bumshick Shin (iD) and KyuHan Kim \\ Catholic Kwandong University, Gangneung, Republic of Korea \\ Correspondence should be addressed to Bumshick Shin; bs.shin@gmail.com
}

Received 2 September 2017; Revised 12 November 2017; Accepted 17 January 2018; Published 10 April 2018

Academic Editor: Young-Jin Cha

Copyright (c) 2018 Bumshick Shin and KyuHan Kim. This is an open access article distributed under the Creative Commons Attribution License, which permits unrestricted use, distribution, and reproduction in any medium, provided the original work is properly cited.

\begin{abstract}
Recently, advancement of digital image techniques and communications technology has enabled the application of existing images for scientific purposes. Furthermore, both quantitative and qualitative analyses of images have become possible through image processing such as transmit/storage of digital image data and image rectification. In this study, a coast having representative characteristics of east coast of Korea was selected with having erosion in winter, and the sedimentation in summer takes place repeatedly. Three-dimensional hydraulic model test was conducted to analyze its outcomes by a digital image correlation technique in order to understand the wave-induced current affecting the sediment transport. For this study, images filmed by the high-sensitive and high-resolution video camera were converted into stopped images of regular intervals and then those converted images were used for the following procedure to analyze flow and velocity into digital coordinates. The outcomes from interpretation of images filmed by the high-sensitive and high-resolution video camera can be utilized as a very useful analysis method for appreciating the generation mechanism and movement route of longshore current and rip current.
\end{abstract}

\section{Introduction}

When acquiring information of wave and current in a wide sandy beach, a number of measuring instruments are needed which is time-consuming and inefficient in economical purposes. Nonetheless, recent advancement of digital image techniques and communications technology has enabled the application of existing images for scientific purposes. Furthermore, both quantitative and qualitative analyses of images have become possible through image processing such as transmit/storage of digital image data and image rectification. Especially, these methods are useful in long-time observation without much cost that are employed for studies on coastal phenomena or coastal changes. In order to study the uprush of waves along coastline, Holman and Guza introduced the Argus time-lapse photography technique [1]. Holman and Lippmann [2] developed the technique for the observation of a three-dimensional shape of offshore bar which measures the topography and scale of natural offshore based on the shape of incoming breaking waves by the application of remote observation technology.
Holman et al. [3] showed an example of measuring the depth of water at coasts by using videos which caused less cost even for a longer period of time. Lippmann and Thornton [4] employed stereo video analysis technique to measure sea level rise, beach slope, and visibility. Liang and Puleo [5] applied an image interpretation technique to measure the surface flow. Vos [6] first noted observations of the developmental stages of a transient rip current on the Western coast of Australia. Symonds et al. [7] further characterized the development and decay of a rip with time-exposed video imagery.

The image sensor used for image interpretation, which is a semiconductor module converting optical images into electric signals, can be referred to as a kind of electronic part used for reproducing optical images in device for storing, transmitting, and displaying images. Generally, there are two types of image sensors, which are CCD and CMOS. CCD has the features of having less noise and better image quality than the CMOS while production of CMOS cost and power consumption is lower than that of CCD. Also, CMOS makes it easier for peripheral circuits to be integrated into identical 
chips. Arita and Deguchi [8] introduced a considerable number of studies that have been conducted on the spatial wave distributions by using two CCD video camera images. These studies analyzed azimuth difference of digital images taken by video cameras.

In this study, the authors proposed the procedure to measure surface profile by applying stereo matching method of two images of the sea surface without any targets or tracers. IPX-11M5-GCxx made up of CCD image sensors with superior image quality and less noise was employed for the interpretation of video image data through digital image processing technique to analyze the generation and flow of wave-induced current.

\section{Description of Digital Image Correlation Techniques}

2.1. Image Coordinate Using Photogrammetry. The basis of understanding stereo imaging is the pinhole camera model which can be seen in the figure below [9]. The process of image interpretation is based on geometry having principles of photogrammetry. The position of a coordinate can be expressed as a function of the position on the ground corresponding to the position, the focal length, and the tilt of camera, swing, azimuth, and elevation. Formulas are expressed in the following:

$$
(x, y)=f\left(X, Y, Z_{c}, f_{c}, t, f, s, H\right),
$$

where $(x, y)$ and $X, Y, Z_{c}$ mean the coordinate in the image and the real coordinate on the ground which correspond to $(x, y)$ in the image, respectively. And $f_{c}, t, s$, and $H$ mean the focal distance of the camera, tilt of the camera (upward from horizontal axis), azimuth (counter clockwise), sing or the roll angle, and the height from the origin of the coordinate, respectively.

2.2. Projective Transformation. Images have to be filmed vertically from the selected sea area for higher accuracy; however, it is not easy to obtain any vertical image. Therefore, the peripheral structures in the subject area should be filmed to get sloped images so that a digital orthoimage may be obtained through projective transformation as shown in Figure 1. The digital orthoimage, a fundamental principle of photographic survey, is based on a geometric condition of collinearity condition which arbitrary points in a space (or points of a subject: $X p, Y p$, and $Z p$ ), the points $(x, y)$ on the photo corresponding to them, and the filming focus on the photo $\left(X_{0}, Y_{0}\right.$, and $\left.Z_{0}\right)$ should be collinear.

When using collinearity condition, $Z$ in (2) becomes the same, and the height of the cameras is always consistent and produces the projective transformation formula as shown in (3). This formula is valid when the sloped and vertical plane of the measured subject surface is flat even if it is not horizontal, where the coordinate transformation becomes possible with the evaluation of b1-b8. Moreover, the control points more than 4 are needed for the evaluation of $\mathrm{b} 1-\mathrm{b} 8$ parameters. Through the evaluation of the position $\left(X_{0}, Y_{0}\right.$, and $\left.Z_{0}\right)$ of the camera, taking pictures and its slope $(\kappa, \psi, \omega)$ with the applied collinearity condition will lead to

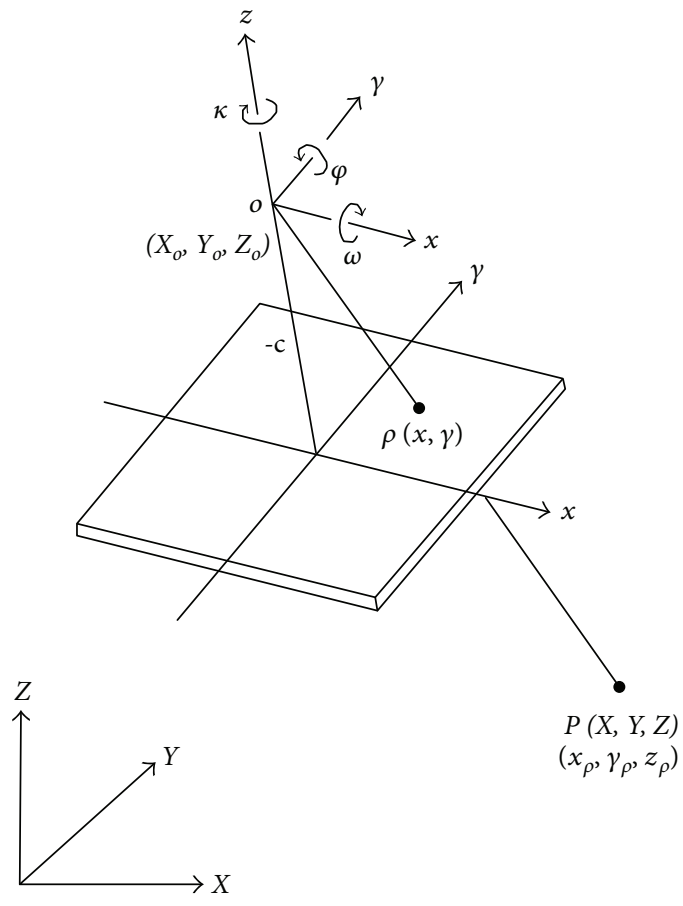

Figure 1: Projective transformation.

the correlation between photo coordinate $(x, y)$ and ground coordinate $(X, Y$, and $Z$ ) where $C$ is the focal distance.

$$
\begin{aligned}
& X=\frac{b_{1} x+b_{2} y+b_{3}}{b_{7} x+b_{8} y+1}, \\
& Y=\frac{b_{4} x+b_{5} y+b_{6}}{b_{7} x+b_{8} y+1}, \\
& x=-c \frac{x_{p}}{z_{x}}, \\
& y=-c \frac{y_{p}}{z_{y}} . \\
& \left(\begin{array}{c}
x_{p} \\
y_{p} \\
z_{p}
\end{array}\right)=\left(\begin{array}{ccc}
1 & 0 & 0 \\
0 & \cos \omega & \sin \omega \\
0 & \sin \omega & \cos \omega
\end{array}\right)\left(\begin{array}{ccc}
\cos \varnothing & 0 & \sin \omega \\
0 & 1 & 0 \\
-\sin \omega & 0 & \cos \varnothing
\end{array}\right) \\
& \cdot\left(\begin{array}{ccc}
\cos \kappa & -\sin \kappa & 0 \\
\sin \kappa & \cos \kappa & 0 \\
0 & 0 & 1
\end{array}\right)\left(\begin{array}{c}
X-X_{0} \\
Y-Y_{0} \\
Z-Z_{0}
\end{array}\right) .
\end{aligned}
$$

\section{Hydraulic Model Test and Image Interpretation}

In this study, a coast having representative characteristics of east coast of Korea was selected with having erosion in winter, and the sedimentation in summer takes place repeatedly. Three-dimensional hydraulic model test was conducted to 
TABLE 1: Wave basin and directional wave maker specifications.

\begin{tabular}{lccc}
\hline & & Specifications & Scene \\
\hline Wave basin & Wave boards & $40 \mathrm{~m}(\mathrm{~L}) \times 32 \mathrm{~m}(\mathrm{~W}) \times 1.5 \mathrm{~m}(\mathrm{H})$ \\
& Wave maker & $0.75 \mathrm{~m}(\mathrm{~W}) \times 1.5 \mathrm{~m}(\mathrm{H})$ & $36 \mathrm{~m}(0.75 \mathrm{~m} \times 48 \mathrm{ea})$ \\
& Max wave & $0.5 \mathrm{~m}$ \\
Wave maker & Period range & $0.5 \mathrm{sec} \sim 5.0 \mathrm{sec}$ & \\
& Type & Snake \& piston type (AE servo motor)
\end{tabular}
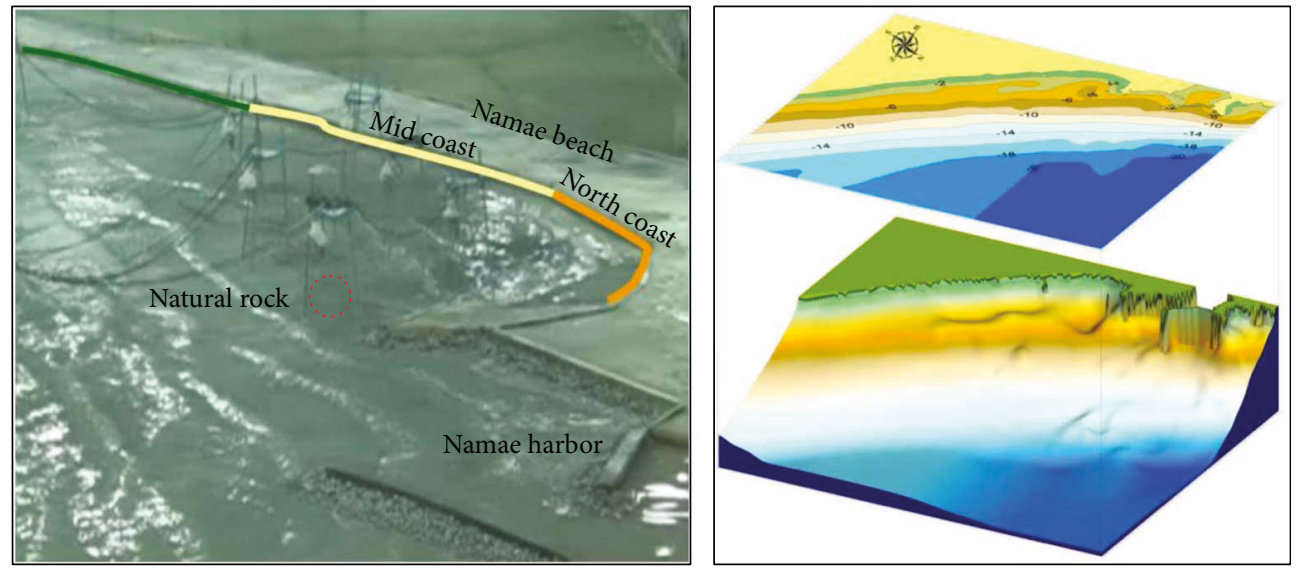

FIGURE 2: Bottom topography and experimental setup.

TABle 2: Camera specifications.

\begin{tabular}{lcc}
\hline & & Specifications \\
\hline Model & & PX-4M15-LCFN \\
Manufacturer & Pixel & KYOCERA \\
& Data clock & $2048 \times 2048$ \\
Spec & Frame rate & $40 \mathrm{MHz}$ \\
& Shutter speed & $15 \mathrm{fps}(\mathrm{dual}), 118 \mathrm{fps}(\max )$ \\
& & $1 / 20000 \sim 1 / 7 \mathrm{sec}$
\end{tabular}

analyze its outcomes by a digital image correlation technique in order to understand the wave-induced current affecting the sediment transport.

3.1. 3D Hydraulic Model Test. A 3D hydraulic model test, which was reduced according to similarity law, was carried out at the topography of real sea for the review of the applicability of wave-induced current monitoring through image interpretation technique $[10,11]$. For this experiment, the high-sensitive and high-resolution video camera image interpretation system including CCD image sensor which is to be applied at the fields was employed for filming as shown in Table 1.

3.2. Modelling. The model considered that water flows from south to north for both summer and winter, so it reproduced a range of $1500 \mathrm{~m}$ of south and $900 \mathrm{~m}$ of north including Namae port with Namae beach in the center where waveinduced current can be affected. The study is located at Namae beach at the center of a wave generator and a basin in order to earn the optimal estimation result as shown in Figure 2.

Moreover, $2.2 \mathrm{~km}$ is selected from coast line to offshore to simulate water depth of $20 \mathrm{~m}$ that may have an effect on incident wave. The model and water level production used recently published Digital Maritime Chart and site survey of water depth data by Korea Hydrographic and Oceanographic Administration.

3.3. Image Process. In the 3D hydraulic model test, quantitative data have been acquired through image digitalization, 


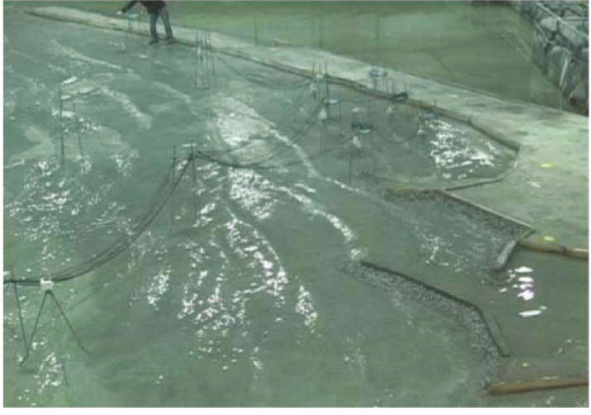

Figure 3: Before projective transformation.

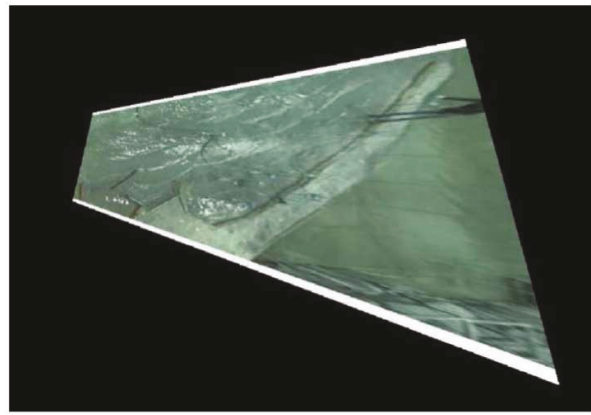

FIgURE 4: After projective transformation. coordinate rectification, and image processing after filming of the physical phenomena such as waves and current generated along with the movement of wave makers by the high-sensitive and high-resolution video camera (IPX-11M5-GCxx). Table 2 shows the image sensors applied for filming. A considerable number of studies have been conducted on the spatial wave distributions by using two video camera images. These studies analyzed azimuth difference of digital images taken by video cameras. In this study, the authors proposed the procedure to measure surface profile by applying stereo matching method of two images of the sea surface without any targets or tracers. The validity of the proposed procedure was examined through the experiment in a wave basin.

For this study, images filmed by the high-sensitive and high-resolution video camera were converted into stopped images of regular intervals and then those converted images were used for the following procedure to analyze flow and velocity into digital coordinates.

(1) Filming: creation of stopped images of regular interval (40 seconds) from filmed video images

(2) Control point measuring: total station used for measuring control points which would be applied in case of any change to the shapes of shore protection or to protection

(3) Protective transformation: 9 control points measured by total station adopted for protective transformation of stopped images to create vertical digital orth image as shown in Figures 3 and 4

(4) Calibration: confirmation to see if protective transformation was carried out correctly after comparing the outcomes of control point measurement with the images after protective transformation

(5) Image extraction (wave-induced current image analysis): pixels of water-blue part by the application of RGB image data to each image

(6) Creation of image data: marking the extracted pixels on coordinate system

3.4. Simulation Results. Flow pattern of wave-induced current from three-dimensional hydraulic model test and field investigation data was similar in many parts. In the test, we observed the longshore current which flows from south to north in ENE, ESE wave direction was the dominant flow pattern, and current velocity was $0.28 \mathrm{~m} / \mathrm{sec}$ during ESE wave direction and $0.16 \mathrm{~m} / \mathrm{sec}$ during ENE wave direction. Flows that generated from the south was moving along the beach in forms of longshore current, and it was changed into rip current at near the underwater rock, moving to offshore. Meanwhile, some currents that start from headland of north beach were moving toward to the beach and were transformed into rip current at the same place. We observed that rests were not moving to the open sea but were stagnated at harbor entrance located in the north. It proves that harbor siltation at harbor entrance was generated not only in summer but also in other seasons.

The result of the test is shown in Figure 5 and was analyzed by PIV method. Generally, beach transformation of the coast occurs daily in a short term and several years in a long term. But constant beach transformation may lead to transformations in heights and surface areas in overall coast area. Since current videos have too low resolution to monitor a beach transformation for the transformation investigation in units of centimeter, we considered the characteristics of coast and its surface to find the causes of beach transformation. VMS (video metric systems) and PIV (particle image velocimetry) methods were applied to overcome the limits of resolution and location with several camera installations. As a result, analysis of sea marker's flow state showed a velocity of moving flow of $0.12 \sim 0.28 \mathrm{~m} / \mathrm{sec}$.

Those filmed images were interpreted, compared with those results from digital model test and hydraulic model experiment for verification, and also compared with the results of field observation by Shin and Kim [12]. The interpretation of images filmed from 3D hydraulic model test showed that wave-induced current was moving from south to north with the velocity of $0.2 \sim 0.5 \mathrm{~cm} / \mathrm{sec}$, which outcomes were estimated to be similar to those from digital model test of Kim et al. [10], and also confirmed to have the same characteristic as a result of peak velocity measured at hydraulic model test. Moreover, comparison with the outcomes of field observation by Kim and Shin [12] revealed that these comparisons corresponded with the analysis results of wave-induced current by the digital image correlation technique. 

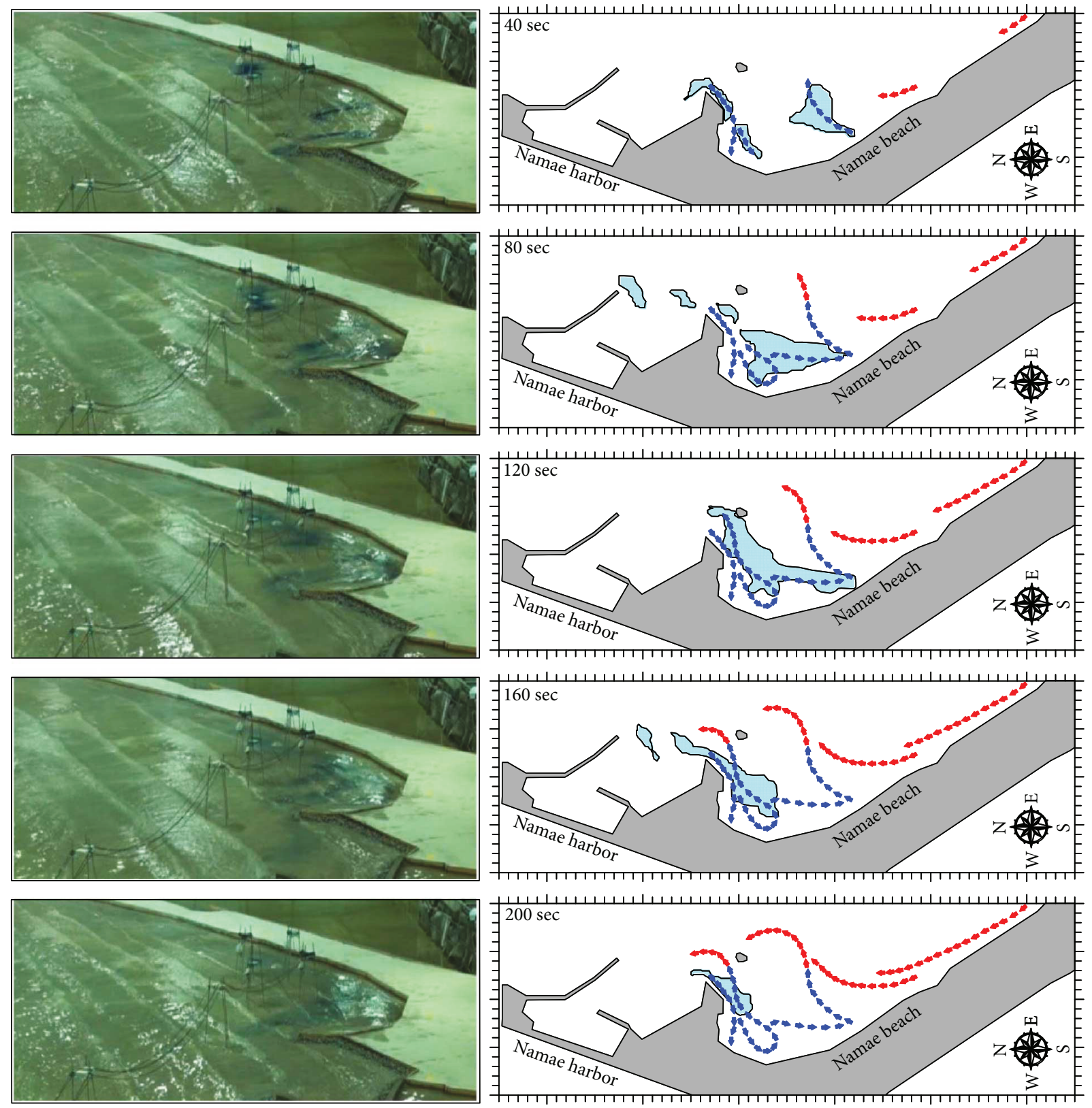

$\Rightarrow$ Digital measurement
$\Rightarrow$ Visual measurement

FIGURE 5: Flow patterns of wave-induced current in 3-dimensional hydraulic model test.

\section{Conclusion}

In this study, images obtained by unit-hour in specific time zones were extracted from the ground of images filmed by high-sensitive and high-resolution video cameras so as to improve the existing dot-unit measuring method to planeunit measuring method. Also, those image data were geometrically corrected, which were applied for reviewing generating mechanism and moving route of wave-induced current. The interpretation of images enabled the confirmation of generation routes of longshore current and strong rip current, which results were found to have a very similar tendency to those of point measurement at preceding hydraulic model tests, flow direction and flow velocity measured at digital model test, and plane unit at field observation.

The outcomes from interpretation of images filmed by the high-sensitive and high-resolution video camera can be utilized as a very useful analysis method for appreciating the generation mechanism and movement route of longshore current and rip current. As a result, the paths of longshore current and strong rip current were found. It is expected that the video metric system employed in this study will be 
effectively utilized in field tests in the near future to further study the mechanism of wave-induced current occurrence and its paths.

\section{Conflicts of Interest}

The authors declare that they have no conflicts of interest.

\section{References}

[1] R. A. Holman and R. T. Guza, "Measuring run-up on a natural beach," Coastal Engineering, vol. 8, no. 2, pp. 129-140, 1984.

[2] R. A. Holman and T. C. Lippmann, "Remote sensing of nearshore bar systems-making morphology visible," in Proceedings of Coastal Sediments '87, ASCE, pp. 929-944, New York, NY, USA, 1987.

[3] R. A. Holman, A. H. Sallenger, T. C. Lippmann, and J. W. Haines, "The application of video image processing to the study of nearshore processes," Oceanography, vol. 6, no. 3, pp. 78-85, 1993.

[4] T. C. Lippmann and E. B. Thornton, "Observation of surf zone wave breaking during Duck 94," in 25th International Conference on Coastal Engineering: Book of Abstracts, pp. 720-721, Orlando, FL, USA, 1996.

[5] H. Liang and J. A. Puleo, "PIV measurements of surface flows in laboratory wave basins," Journal of Flow Visualization and Image Processing, vol. 16, no. 1, pp. 1-18, 2009.

[6] R. G. Vos, "Observations on the formation and location of transient rip currents," Sedimentary Geology, vol. 16, no. 1, pp. 15-19, 1976.

[7] G. Symonds, R. A. Homan, and B. Bruno, "Rip currents," in Proc. Coastal Dynamics '97, pp. 584-593, 1997.

[8] M. Arita and I. Deguchi, "Measurement of wave surface using digital video camera," Proceedings of the Coastal Engineering, JSCE, vol. 54, pp. 1426-1430, 2007.

[9] B. Jähne, Practical Handbook on Image Processing for Scientific Applications, CRC Press, Inc., Boca Raton, FL, USA, 1995.

[10] K. H. Kim, H. S. Yoo, and N. Kobayashi, "Mitigation of beach erosion after coastal road construction," Journal of Coastal Research, vol. 274, no. 4, pp. 645-651, 2011.

[11] K. H. Kim and J. S. Seo, "Investigation of characteristics of wave induced currents using hydraulic model experiment," in Proceedings of the 2016 International Conference on Applied Engineering, Materials and Mechanics (ICAEMM 2016), pp. 267-272, Weihai, China, 2016.

[12] B. S. Shin and K. H. Kim, "Rip current monitoring using video analysis," Journal of Coastal Research, vol. 72, pp. 28-32, 2014. 




\section{Enfincering}
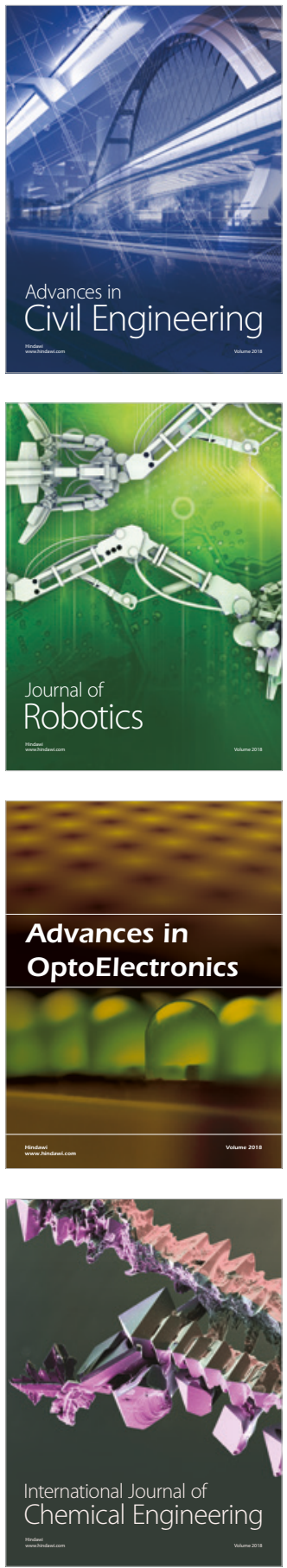

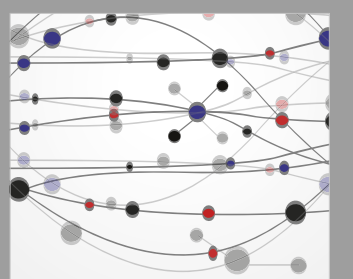

\section{Rotating \\ Machinery}

The Scientific World Journal

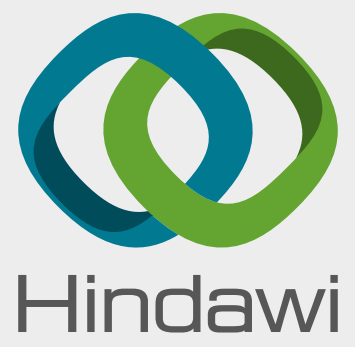

Submit your manuscripts at

www.hindawi.com
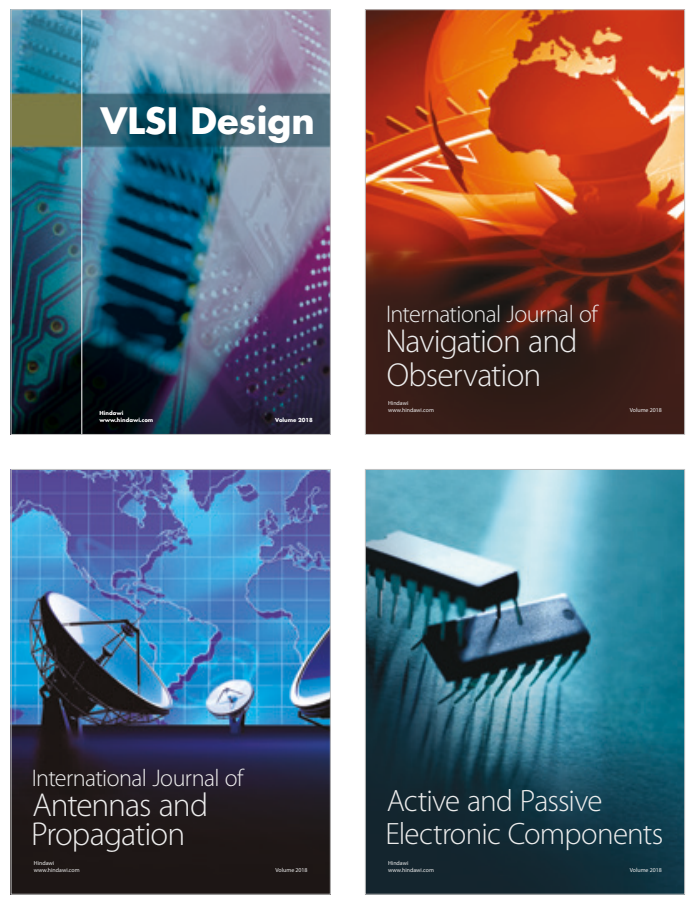
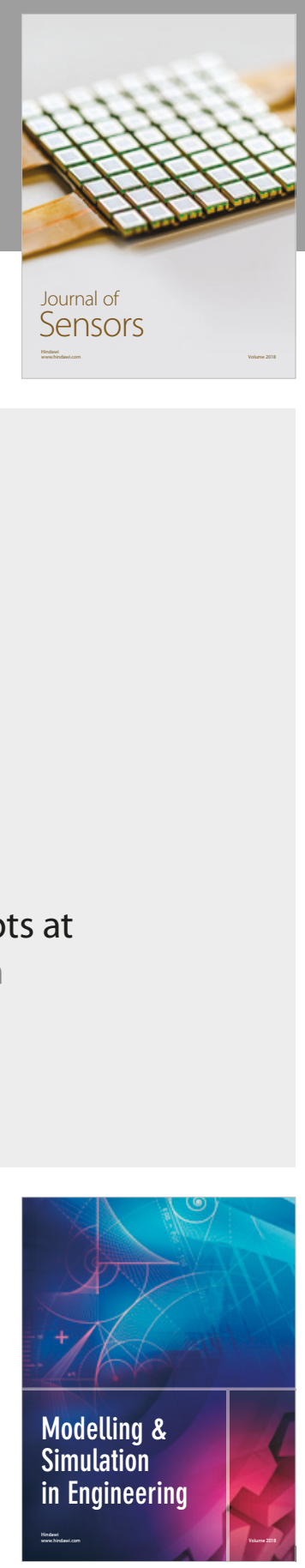

\section{Advances \\ Multimedia}
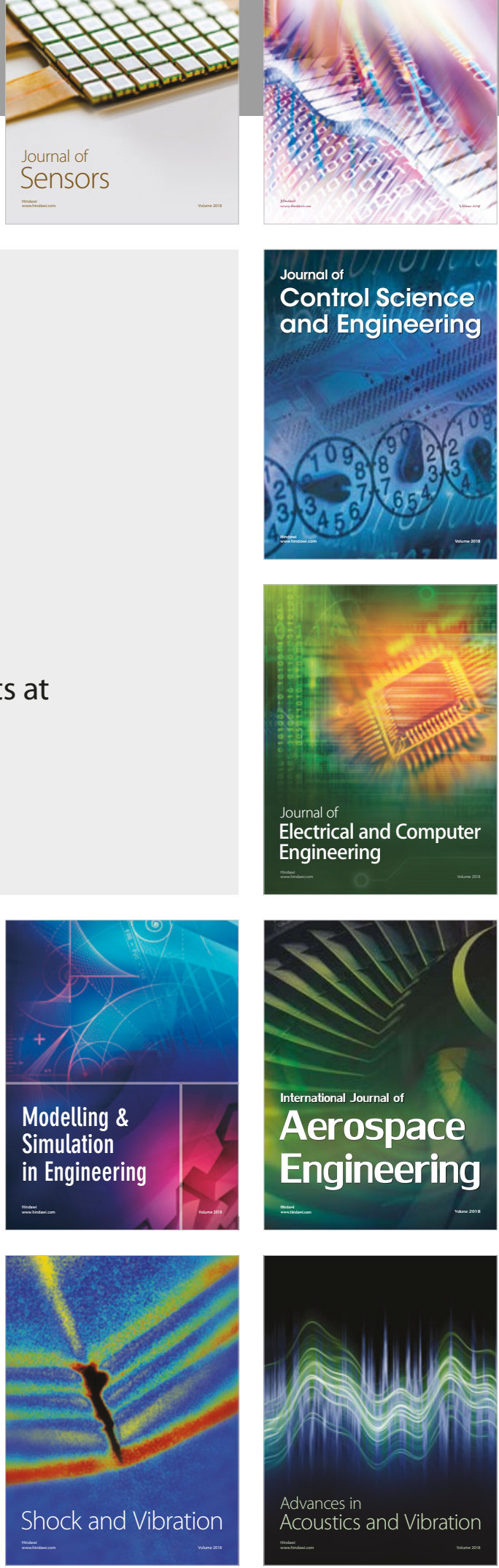